
\title{
$\begin{array}{ll}\text { Research Square } & \begin{array}{l}\text { Preprints are preliminary reports that have not undergone peer review. } \\ \text { They should not be considered conclusive, used to inform clinical practice, } \\ \text { or referenced by the media as validated information. }\end{array}\end{array}$
}

\section{CYP-450 Mediated Herb-Drug Interactions of Ashwagandha and AYUSH-64 Used in COVID-19 Integrative Management: A Case Example of Remdesivir}

\section{Siva Swapna Kasarla}

Translational Health Science and Technology Institute (THSTI), NCR Biotech Science Cluster, 3rd Milestone, Faridabad, Haryana https://orcid.org/0000-0002-0802-5849

Swapnil Borse ( $\nabla$ spborse@gmail.com )

AYUSH - Center of Excellence (AYUSH-CoE), Center for Complementary and Integrative Health [CCIH], Interdisciplinary School of Health Sciences (ISHS), Savitribai Phule Pune University,Pune https://orcid.org/0000-0003-4246-6522

Yashwant Kumar ( $\nabla$ y.kumar@thsti.res.in )

Translational Health Science and Technology Institute (THSTI), NCR Biotech Science Cluster, 3rd Milestone, Faridabad

\section{Neha Sharma}

Translational Health Science and Technology Institute (THSTI), NCR Biotech Science Cluster, 3rd Milestone, Faridabad

Madhu Dikshit ( $\square$ madhudikshit@yahoo.com )

Translational Health Science and Technology Institute (THSTI), NCR Biotech Science Cluster, 3rd Milestone, Faridabad; Current address CSIR- Central Drug Research Institute, Sitapur Rd, Sector 10, Jankipuram Extension, Lucknow, Uttar Pradesh

\section{Research Article}

Keywords: Withania somnifera, Ayurveda, Remdesivir, Integrative Medicine, Rasayana, LC-MS/MS

Posted Date: December 29th, 2021

DOI: https://doi.org/10.21203/rs.3.rs-1201240/v1

License: (c) (1) This work is licensed under a Creative Commons Attribution 4.0 International License. Read Full License 


\section{Abstract}

Aim

Withania somnifera Dunal (WS), known as Ashwagandha and AYUSH-64, a polyherbal formulation are repurposed for the management of COVID-19. The extensive use of these botanicals as home remedy along with other drugs for managing multifarious disease conditions is increasing over nations. This raises high chances of herb-drug interactions (HDIs) which may be beneficial, harmful, or even fatal. Therefore, current study aimed to explore the CYP mediated herb-drug interactions (HDIs) of Ashwagandha and AYUSH-64 along with case example of remdesivir to harness the best of these HDls for integrative management of COVID-19

\section{Materials and Methods}

The aqueous extract of Ashwagandha and AYUSH-64 were characterized by LC-MS/MS. The in-silico pharmacokinetic (ADME) parameters were studied by using ADME tool. The in-vitro CYP-450 (CYP3A4, 2C8, 2D6) inhibition studies of WS and AYUSH-64 alone and in combination with a remdesivir were carried out resembling clinically scenario.

\section{Results}

Total of 11 and 24 phytoconstituents were identified from the aqueous extract of Aswagandha and AYUSH-64. The in-silico ADME studies revealed that most of the phytoconstituents showed good oral bioavailability, drug likeliness, $\mathrm{Gl}$ affinity and some of them displayed CYP-450 inhibitory activity. The in-vitro CYP-450 studies of remdesivir showed moderate inhibitory effect on CYP3A4, 2C8, 2D6. The aqueous extract of Aswagandha did not show any inhibitory activity towards all the studied CYP's alone and in combination with remdesivir (IC50 $>100 \mu \mathrm{g} / \mathrm{ml}$ ). Whereas, AYUSH-64 also followed the same trend but showed moderate inhibitory effect on CYP2C8 $($ IC50 $<100 \mu \mathrm{g} / \mathrm{ml})$.

\section{Conclusion}

Aswagandha did not exhibit HDIs with the CYP3A4, CYP2C8 and CYP2D6 thereby seem to be safe to co-administer with respective substrates. Whereas, AYUSH-64 only showed moderate HDIs towards CYP2C8 substrate among studied CYP enzymes. Caution is therefore warranted for prescribing AYUSH 64 along with CYP2C8 substrate drugs.

\section{Introduction}

Modern system of medicine has emerged as the primary choice for the treatment of nearly all types of health-related issues (1). On the other hand, the Traditional Complementary and Alternative Medicine (TCAM or CAM) like Ayurveda, Siddha, Unani, Sowa-Rigpa, Chinese medicine, etc. are gaining popularity due to their higher safety and long-term efficacy (2). The currently available treatment modalities of modern medicine as well as CAM are still struggling to handle the multi-factorial chronic disorders like cancer, diabetes, arthritis, COVID-19, etc. $(1,2)$. Therefore, there is need to find the way to use the strengths of both systems of medicines for betterment of health care sector. But, the patients of such chronic illnesses directly/indirectly take combinational/multimodal therapy with or without the knowledge of physicians, leading to potential herb-drug interactions (HDIs) (3).

The World Health Organization (WHO) data and literature shows that, more than 70-80\% world's population uses CAM for their health care needs. Particularly in western countries CAM has become increasingly popular over the last few decades $(1,2)$. The health-seeking behaviour studies from various parts of the world suggests widespread use of TCAM in noncommunicable diseases (NCDs) (4-6). This pattern is similar in high-income countries as well as low and middle-income countries. Most of the countries do not have evidence-based policies nor regulations to rationale the concomitant utilization of therapies (3). This phenomenon needs systematic scientific investigations, especially for herb-drug interaction studies. This study will be important in the Indian scenario where most of the patients use herbs and drugs together. However, concomitant usage of herbs and conventional medicines globally could be much higher as healthcare professionals often do not ask about herbal remedies when prescribing and patients do not volunteer that they are taking them $(2,3)$. Indeed, such a scenario of concomitant usage of herbs/CAM and conventional medicines brings with it the potential problem of HDI's and this issue has emerged as a major hurdle/problem in our journey towards integrative medicine (IM) (7). 
Integrative medicine refers to the blending of conventional and evidence-based complementary medicines and therapies with the aim of using the most appropriate of either or both modalities for efficient patient care $(2,7,8)$. In short, IM utilizes all appropriate, evidence-based therapies to achieve health. For example, Aswagandha, have been widely accepted as a novel complementary therapy for integrative oncology care (9). Aswagandha, AYSUH-64, Tinospora cordifolia, Piper longum, etc. are being strongly exploited in the integrative management of COVID-19 (10-16). In addition, to that they are also being used as home remedies to combat the various communicable and non-communicable diseases (10-16). In addition to this, patients of such chronic illnesses directly/indirectly take multimodal therapy with or without the informing to the physicians, leading to potential HDIs. Such HDIs may be beneficial, harmful or even fatal (17).

HDIs may possibly observed, both at pharmacodynamic and pharmacokinetic (at any stage of ADME) level (18). The interactions at the site of metabolism are eminently noticed due to their complex metabolic processes (2). Most of the xenobiotics and herbal drugs are known to metabolise by phase I metabolising enzymes rather than Phase II. Of which, cytochrome P450 mediated phase I metabolising enzymes accounts for xenobiotic transformation of $90 \%$ of drugs and herbal medicines $(19,20)$. In order to anticipate the possible drug interactions at the metabolism site for better therapeutic and safety profiles of IM, it is always necessary to study the metabolic interactions of both allopathic and herbal drug candidates (21). Despite of all 60 CYP isoforms that are available in human genome, the six CYP enzymes namely $1 \mathrm{~A} 2,2 \mathrm{C} 8,2 \mathrm{C} 9,2 \mathrm{C} 19,2 \mathrm{D} 6$ and $3 \mathrm{~A} 4$ are majorly engaged in the metabolism of $70-90 \%$ of drugs (20).

Therefore, the present study focuses assessing the probable HDIs associate with the use of Aswagandha and AYUSH-64 in the management of COVID-19. In this paper, we have performed the phytochemical characterization of Aswagandha and AYUSH-64 by LC-MS/MS. The in-silico pharmacokinetic (ADME) parameters were explored for the identified phytoconstituents of both the herbal extracts. We have also used remdesivir (key antiviral, antiCOVID-19 drug) as a representative example for HDI studies. As the remdesivir gets metabolised by CYP3A4, 2C8, and 2D6 so, the studies on the above listed selected CYP enzymes have a profound importance to predict clinical HDIs for effective and safe management of the disease due to probable HDIs.

\section{Material And Methods}

\subsection{Chemicals reagents and solvents}

Testosterone, ketoconazole, 6ß-hydroxy testosterone, paclitaxel, rosiglitazone, remdesivir, NADPH, 6-hydroxy paclitaxel, dextromethorphan $\mathrm{HBr}$, dextrorphan, quinidine, NADPH, Mixed gender HLM (Human liver microsomes: Pool of 50) were received from Sigma Aldrich. Pvt. Ltd, India. Water, methanol, acetonitrile of LC-MS grade was procured from Merck life science, Pvt. Ltd, India. The aqueous extracts of Withania somnifera and AYUSH-64 were received from Central Council for Research in Ayurvedic Sciences (CCRAS), Ministry of AYUSH, Govt. of India. The aqueous extract of Aswagandha where prepared as per the Ayurvedic procedure. Whereas the AYUSH 64 is a polyhedral formulation prepared as per Ayurvedic logic which established marketed product of CCRAS as an Ayurvedic Proprietary Medicine.

\subsection{Phytochemical characterization of Aswagandha and AYUSH-64 by using LC-MS/MS}

The lyophilized aqueous extracts of Aswagandha and AYUSH-64 was reconstituted at a concentration of $10 \mathrm{mg} / \mathrm{mL}$ in $100 \%$ methanol followed by sonication of about $30 \mathrm{~min}$. The sample was further filtered by using $0.2 \mathrm{~mm}$ filter and LC-MS/MS was used to characterize the extract. The HSS-T3 C18 column $(2.1 \times 100 \mathrm{~mm}, 1.8 \mu \mathrm{m}, 100 \AA$; Waters Corporation) were used in "UHPLC Ultimate 3000 " and the column oven temperature was maintained at $40^{\circ} \mathrm{C}$. Mobile phase A and B contains water with $0.1 \%$ formic acid and acetonitrile with $0.1 \%$ formic acid respectively. The gradient elution starts with $1 \%$ B to $95 \%$ B over 14 min (22). The Orbitrap Fusion Mass Spectrometer fitted with heated electrospray ionization (HESI) was operated for positive mode (+ve) at $1,20,000$ resolution in MS1 mode and 30000 resolution in data-dependent MS2 scan mode. The spray voltage used for these positive and negative modes is 4000 and 35000 volts respectively. Sheath gas and auxiliary gas were set to 42 and 11 respectively. The mass scan range was 50-1000 m/z, AGC (Automatic gain control) target at 200000 ions and maximum injection time was 80 ms for MS and AGC target was 20000 ions and maximum injection time 60 ms for MS-MS was used (22). Data processing was done using Thermo scientific Xcalibur software and the identification of metabolite was confirmed by accurate mass and MS/MS fragmentation match of the metabolites available from the literature and mzCloud database. 
The list of characterised phytochemicals was further used for predicting HDIs for safe and effective usage along with drugs used in the management of the COVID-19 and associated comorbidities. Thereby, the in silico pharmacokinetic studied were explored by using SwissADME tool (23).

\subsection{CYP Inhibition Activity Assay}

CYP3A4, 2C8, 2D6 inhibition activity assays were carried out by using pool of 50 human liver microsomes (HLM) having protein concentration of $10 \mathrm{mg} / \mathrm{ml}$. Testosterone $(70 \mu \mathrm{M})$, paclitaxel $(5 \mu \mathrm{M})$, and dextromethorphan $(5 \mu \mathrm{M})$, are used as a probe substrate for CYP3A4,

$2 \mathrm{C} 8$, and 2D6 respectively. The marker metabolites $6 \beta$-hydroxy testosterone, 6-hydroxy paclitaxel, and dextrorphan were used for the measuring the enzyme activity. For each isozyme, aliquot $99.5 \mu \mathrm{L}$ of incubation mixture (containing HLM and substrate) was spiked with $0.5 \mu \mathrm{L}$ of investigational plant drug/positive control/remdesivir working solution in a microcentrifuge tube and mixed by swirling and mild shaking. Thereafter, $10 \mu \mathrm{L}$ of $10 \mathrm{mM}$ NADPH was added to initiate the reaction to all microcentrifuge tubes and incubated for $10 \mathrm{~min}$ at $37^{\circ} \mathrm{C}$. The incubation reactions were stopped with addition of $400 \mu \mathrm{L}$ quenching solution (\%100 methanol) (24). The samples were centrifuged at $10000 \mathrm{rpm}$ for $5 \mathrm{~min}$. The supernatant was analysed by LC-MS/MS. The positive control inhibitor incubations were prepared similarly and analysed concurrently. Whereas the blank was prepared by spiking DMSO instead investigational plant drug. All the experiments were carried out in triplicates.

\subsection{Preparation of test solution and positive control}

The investigational plant drugs (Aswagandha and AYUSH-64) were prepared in 7 different concentrations ranging 2000, 1000, 100, $50,20,10,1 \mu \mathrm{g} / \mathrm{ml}$. Stock solution of $500 \mathrm{mg} / \mathrm{ml}$ of investigational plant drugs was prepared with water and kept overnight in a mechanical shaker at a speed of $200 \mathrm{rpm}$ at $37^{\circ} \mathrm{C}$. The solutions were centrifuged at 10,000 rpm for 30 min and the supernatant collected was used for further analysis. The concentration ranges for positive controls were 5.00-0.0005 $\mu \mathrm{M}, 1.00-0.01 \mu \mathrm{M}, 5.00$ $0.0005 \mu \mathrm{M}$ ketoconazole (CYP3A4) (24), rosiglitazone (CYP2C8) (25), and quinidine (CYP2D6) (26) respectively. The concentration of case control small molecule remdesivir were prepared in the range of $1000-1 \mathrm{ng} / \mathrm{ml}(27)$.

\subsection{Measurement of marker metabolites by LC-MS/MS method}

The marker metabolites (6- $\beta$-hydroxy testosterone, 6-hydroxy paclitaxel and dextrorphan) formed as a result of metabolism by respective CYP3A4, CYP2D6, and CYP2C8 substrates (testosterone, paclitaxel, and dextromethorphan) were measured by using LCMS/MS method.

The chromatography separations are carried out as mentioned above. The water with $0.1 \%$ formic acid is used as mobile phase $\mathrm{A}$ and methanol and $0.1 \%$ formic acid as mobile phase $B$. The run time of $14 \mathrm{~min}$ with a flow rate of $0.300 \mathrm{ml} / \mathrm{min}$ were used. The method was followed as reported in the section 2.2

\subsection{Data processing and targeted metabolite analysis}

Thermoscientific Xcalibur system was used for data processing and data analysis. The standard metabolite retention time and MS-MS fragmentation was matched with sample. The respective metabolite concentration was monitored accordingly under different experimental conditions (CYP3A4, CYP2D6, and CYP2C8).

\subsection{Determination of IC50 values}


The above-mentioned concentrations of investigational herbal drugs (Aswagandha, AYUSH64) were selected on the basis of daily maximum human dose when diluted in $1 \mathrm{~L}$ of gastrointestinal fluid followed by distribution in $56 \mathrm{~L}$ of total body fluid (24). This assumption is based on Ayurvedic properties of these drugs and thereby considering the one compartment modelling distribution $(28,29)$. The percentage of $(\%)$ control activity and $(\%)$ inhibitory activity was calculated using the following formulae: \% control activity $=$ (peak area of metabolite formed in the presence of herbs/peak area of metabolite formed in control) $\times 100$ and $\%$ inhibition activity $=100-\%$ control activity (30).

\subsection{Prediction of probable clinical interactions}

IC50 of CYP substrate (i.e., testosterone, paclitaxel, and dextromethorphan for CYP3A4, CYP2C8, and CYP2D6 respectively) activity in HLM was calculated graphically by nonlinear regression analysis of logarithmic inhibitor concentration (log conc.) versus \% of inhibitory activity plot using GraphPad Prism 5 . The data were expressed as mean \pm standard deviation. Ratio of I/Ki was used to predict plausible clinical interactions and $>0.1$ was considered for possible clinical interaction. [l] is mean maximum surrogate plasma concentration $\left(\mathrm{C}_{\max }\right)$ at steady state after administration of the highest clinical dose of inhibitor in human and used from previously published literature. Inhibitory constant (Ki) was calculated using equation: $\mathrm{Ki}=\mathrm{IC} 50 / 1+[\mathrm{S}] /[\mathrm{Km}]$. [S] and [Km] are substrate concentration and Michaelis constant respectively (24). Since the interaction between ketoconazole and testosterone, rosiglitazone and paclitaxel, quinidine and dextromethorphan are competitive. Therefore, in our experiment, [S] and [Km] values were same. [l] values for ketoconazole were used as 1 to $5 \mu \mathrm{g} / \mathrm{mL}(5 \mu \mathrm{g} / \mathrm{mL}$ was used in the experiment), likewise $100 \mu \mathrm{g} / \mathrm{mL}$ and $5 \mu \mathrm{g} / \mathrm{mL}$ for rosiglitazone and quinidine respectively. It was not possible to calculate $\mathrm{I} / \mathrm{Ki}$ ratio for herbal extracts because of the absence of pharmacokinetics data (31). Instead, it was specified that the IC50 values of plant extracts $<100 \mu \mathrm{g} / \mathrm{mL}$ or $<100$ $\mu \mathrm{M} / \mathrm{mL}$ were considered to be a potent inhibitor of CYP450 enzymes which may results in undesirable HDIs $(24,32)$.

\section{Results}

\subsection{Phytochemical characterization of Aswagandha and AYUSH-64 by using LC-MS/MS techniques}

The plant phytoconstituents were characterised by accurate mass and MS-MS fragmentation pattern match. Briefly 11 and 24 plant phytoconstituents were identified from aqueous extract of Aswagandha and AYUSH-64 (Fig. 1, 2; S2 file; S3 file; S4.file.Tab.1, 2). The certificate of analyses of both the aqueous extracts showed presence of impurities (heavy metals) and microbial load are within the acceptable limit as per the pharmacopeial standards.

Table 1

IC50 of the studied herbal extracts Withania somnifera and AYUSH-64 on CYP3A4, 2C8, 2D6 isoenzyme system

\begin{tabular}{|llll|}
\hline Compound Name & CYP3A4 & CYP2C8 & CYP2D6 \\
\cline { 2 - 4 } & IC50 $(\mu \mathrm{g} / \mathrm{ml})$ & IC50 $(\mu \mathrm{g} / \mathrm{ml})$ & IC50 $(\mu \mathrm{g} / \mathrm{ml})$ \\
\hline Withania somnifera & $528.1 \pm 88.04$ & $233.62 \pm 36.72$ & $161.9 \pm 4.45$ \\
\hline AYUSH-64 & $467.5 \pm 78.61$ & $63.44 \pm 14.9$ & $216.25 \pm 39.5$ \\
\hline Remdesivir + Withania somnifera & $741.95 \pm 5.45$ & $116.39 \pm 39.2$ & $108.68 \pm 23.94$ \\
\hline Remdesivir + AYUSH-64 & $201.92 \pm 13.18$ & $85.21 \pm 18.3$ & $111.05 \pm 5.07$ \\
\hline
\end{tabular}


Table 2

IC50 of the studied CYP substrate inhibitors and remdesivir on CYP3A4, 2C8, 2D6 isoenzyme system

\begin{tabular}{|c|c|c|c|c|c|c|c|c|c|c|c|}
\hline \multirow{2}{*}{$\begin{array}{l}\text { CYP3A4 } \\
\begin{array}{l}\text { Compound } \\
\text { name }\end{array}\end{array}$} & \multicolumn{7}{|c|}{ CYP2C8 } & \multicolumn{4}{|c|}{ CYP2D6 } \\
\hline & IC50 & $\mathrm{Ki}$ & $\mathrm{I} / \mathrm{Ki}$ & $\begin{array}{l}\text { Compound } \\
\text { name }\end{array}$ & IC50 & Ki & $\mathrm{I} / \mathrm{Ki}$ & $\begin{array}{l}\text { Compound } \\
\text { name }\end{array}$ & IC50 & Ki & $\mathrm{I} / \mathrm{Ki}$ \\
\hline $\begin{array}{l}\text { Ketoconozole } \\
(\mu \mathrm{M} / \mathrm{ml})\end{array}$ & $\begin{array}{l}0.348 \\
\pm \\
0.03\end{array}$ & 0.17 & 28.73 & $\begin{array}{l}\text { Rosiglitazone } \\
(\mu \mathrm{M} / \mathrm{ml})\end{array}$ & $\begin{array}{l}3.28 \pm \\
0.21\end{array}$ & 1.6 & 60.9 & $\begin{array}{l}\text { Quinidine } \\
(\mu \mathrm{M} / \mathrm{ml})\end{array}$ & $\begin{array}{l}0.12 \pm \\
0.001\end{array}$ & 0.06 & 83.3 \\
\hline $\begin{array}{l}\text { Remdesivir } \\
\text { (ng/ml) }\end{array}$ & $\begin{array}{l}291.13 \\
\pm \\
40.04\end{array}$ & 145.5 & 6.87 & $\begin{array}{l}\text { Remdesivir } \\
(\mathrm{ng} / \mathrm{ml})\end{array}$ & $\begin{array}{l}161.77 \\
\pm 8.38\end{array}$ & 80.8 & 12.3 & $\begin{array}{l}\text { Remdesivir } \\
\text { (ng/ml) }\end{array}$ & $\begin{array}{l}327.25 \\
\pm 79.5\end{array}$ & 163.6 & 6.1 \\
\hline
\end{tabular}

\subsection{Prediction of herb-drub interaction studies: an in-silico approach}

Previously published data on Aswagandha and its effect on CYPs (in silico \& in vitro) have shown that, the aqueous extracts prepared as per procedure given in Ayurvedic text did not show inhibitory effects $(12,24,32)$. Whereas, the in-silico approach was employed to predict pharmacokinetics of herbal extracts. The radar plots of phytoconstituents of AYSUH-64 showed that most of the compounds showed good oral bioavailability along with good drug likeliness and GI absorption (Fig. 3, S1.File, S4.File.Tab.3,4). In addition, few of the phytoconstituents of AYUSH-64 showed CYP3A4 inhibitory activity followed by inhibitory effect on rest of the CYP enzymes (CYP2D6, 2C8, 2C19, 2C9) to the lesser extent. This is helpful in predicting pharmacokinetic interactions and also to develop safe and effective dosage regimen. For instance, the CYP substrate (drugs) may show increased systemic concentration if their metabolising enzyme is getting inhibited.

\subsection{Inhibitory effect on CYP isoenzyme systems}

The effect of aqueous extracts of Aswagandha, AYUSH-64 and a case control small molecule remdesivir on CYP3A4, 2C8, and 2D6 were studied by using HLM. The inhibitory activity of CYP3A4, 2C8, and 2D6 was studied by using respective probe substrates namely testosterone, paclitaxel, and dextromethorphan respectively and the formation of corresponding metabolites 6- $\beta$ hydroxy testosterone, 6-hydroxy paclitaxel, and dextrorphan was monitored at different concentrations by using LC-MS/MS method.

From the present study, the I/Ki ratio of ketoconazole (CYP3A4 inhibitor) was found to be 28.73. Whereas remdesivir was at 6.87 , which showed moderate / weak inhibition of CYP3A4 compared to respective inhibitor (ketoconazole). The results are consistent with previous reports (Tab.2, Fig.4). On the other hand, Aswagandha and AYUSH-64 alone and in combination with remdesivir did not show any kind of CYP3A4 inhibition as their respective IC50 values are more than $100 \mu \mathrm{g} / \mathrm{ml}$ (Tab.1, Fig 4).

Similarly, the I/Ki ratio of rosiglitazone (CYP2C8 inhibitor) was 60.97 . Whereas I/Ki ratio of remdesivir was 12.36 which might lead to a weak inhibition of CYP2C8 compared to respective the inhibitor (rosiglitazone) (Tab.2, Fig.5). Similarly, Aswagandha alone and in combination with remdesivir did not show any kind of inhibitory effect (IC50>100 $\mu \mathrm{g} / \mathrm{ml}$ ) towards CYP2C8 isoenzyme system. While, AYUSH-64 had moderate to weak inhibitory effect as the IC50 was above $100 \mu \mathrm{g} / \mathrm{ml}$. Whereas, AYUSH-64 in combination with remdesivir $($ IC50 $=85.21 \pm 18.3)$ followed the similar trend (Tab.1, Fig.5).

The I/Ki ratio of quinidine (CYP2D6 inhibitor) and remdesivir was 83.3, 6.1 respectively (Tab.2, Fig.6). The study demonstrates remdesivir to be a weak inhibitor of CYP2D6 as compared to respective inhibitor (quinidine). In addition, Aswagandha and AYUSH64 alone and in combination with remdesivir did not exert any inhibitory effect on CYP2D 6 isoenzyme as the IC50 value was >100 $\mu \mathrm{g} / \mathrm{ml}$ (Tab.1, Fig.6).

The present study indicates that, both the AYUSH drugs seems to be safe to administer along with CYP3A4 and 2D6 substrates. Aswagandha also seems to be safe towards the respective CYP2C8 substrates. But AYUSH-64 has weak to moderate interactions. Hence the prescription should be under the observation of a physician / clinical pharmacist and care should be taken with the drugs that are taken concomitantly given with AYUSH-64. 


\section{Discussion}

At present, although several drugs and therapies are in use to mitigate or to prevent from illness caused by SARS-CoV-2, still the urge towards developing the new medical strategies is needful $(33,34)$. The use of integrative medicine $(\mathrm{IM})$ has become a trend either as a primary (to treat disease/illness) or secondary (to downgrade the prevalence of disease/illness) prevention (35). Moreover, the ideal therapeutic regime to treat COVID-19 should possess multi-targetability for immunomodulatory, adaptogenic, rejuvenating, anti-stress, anti-inflammatory, antiviral activity, etc $(11,12)$. It is also important for such IM pharmacotherapeutic regimen to be safe and efficacious to prevent or control the associated comorbidities. From the previous literature the identified phytocompounds from our study are already profound to elicit immune defence and anti-viral properties by which they might act as an adjuvant to treat COVID-19 (36). The usage of herbal extracts/formulations which are the mixture of large number of phytoconstituents renders to show multiple pharmacological activities as well untoward interactions when administered along with conventional medicines (herb-drug interactions)

(37). Such HDIs can be beneficial, harmful or even fatal. Aswagandha well-known Rasayana

( rejuvenator) also referred as "Indian Ginseng" is well established for its immunomodulatory, adaptogenic, anticancer, antidiabetic, anti-COVID-19 activities, etc (28).

In the present study we have characterized the aqueous extract of Aswagandha and found 11 important withanolide and withanoside glycosides were charecterised based on their MS/MS spectra. These glycosides like withanoside VII, V, X are known to elicit immunomodulatory activity and antiviral activity (38). Similarly, AYUSH-64 a polyherbal formulation, AYUSH64 contains the aqueous extracts of rasayana botanicals namely, Saptaparna bark (Alstonia scholaris R. Br.), Katuki roots (Picrorhiza kurroa Royle ex. Benth), Kiratatikta whole-plant (Swertia Chirata Pexbex. Karst), and Kuberaksha seed (Caesalpinia crista L.) (39) was characterized with the help of MS/MS fragmentation pattern and 24 plant phytoconstituents were identified.

The in-silico pharmacokinetics of Ashwagandha and AYUSH-64 revealed that most of the key phytoconstituents of Aswagandha and AYUSH-64 showed good oral bioavailability, drug like properties and GI affinity. Whilst some of the bioactive compounds showed inhibitory affinity towards cytochrome P450 enzymes (CYP3A4, 2C8, 2C9, 2D6, 1A2). However, the low relative abundance of these molecules might be the reason for the IC50 value below $100 \mathrm{ug} / \mathrm{mL}$. Thereby, the dose reduction may be required to have safe and beneficial HDIs. Whereas, opposite will be applicable for the prodrugs (39). Also, some of the docking studied also revealed the key phytoconstituents like withaferin $A$, viscosalactone $B$, withanolide $A$, vallesamine, neocaesalpin $B$, sweroside, picrine, $\beta$-Caesalpin were profound to show good docking core against COVID-19 (15, 39-41). Furthermore, to assure its safe usage in combination with other conventional drugs used in COVID-19 management and also to prescribe for the patients with other comorbidities, we performed the in-vitro herb drug interactions of aqueous extract of Aswagandha and AYUSH-64 by using human liver microsomes.

For instance, the usage of herbal medicines alone and also in combination of other conventional drugs were profoundly increased in the recent times (30). Hence, it is necessary to address their impact on cytochrome P450 enzymes (which contributes to the major hepatic metabolism of drugs) to understand their plausible metabolic interactions (42). In the present study, to simulate clinical context we incorporated to study the activity of herbs alone, as the selected herbs were already profound to be effective towards SARS-CoV-2. Besides, we also evaluated these extracts in combination with most commonly encountered drug remdesvir as a case example to understand their interaction with common CYP isozymes. For the same, the study design was focused on CYP enzymes that metabolise $60-80 \%$ of xenobiotic spectrum. CYP3A4 alone is responsible for the metabolism of more than $50 \%$ of all xenobiotics prescribed during various illnesses (43). Whereas CYP2C8 and CYP2D 6 are responsible for 5\% and 20\% respectively $(44,45)$. Thereby, the prediction for CYP mediated inhibitory kind of HDIs for the drugs that are substrate of these CYPs can be done for the clinical translational purpose. The remdesivir was the most commonly prescribed for the COVID-19 pharmacotherapeutic management during the second wave of ongoing pandemic (46). It was therefore used as a case example for the in-vitro CYP based HDI studies. As individuals are mainly prone for the concomitant consumption of such herbal formulations with allopathic drugs, hence we also concomitantly subjected HLM to the remdesivir and herbal formulations at the same time. 
Remdesivir is a substrate of CYP3A4, 2D6, 2C8. Results from our study indicated that [l]/Ki ratio of remdesivir towards CYP3A4, $2 \mathrm{D} 6,2 \mathrm{C} 8$ was $38.07,27.04,16.62$ respectively indicating that the specified case molecule showed poor inhibitory kind of potential which consistently supports the literature $(47,48)$. However, the aqueous extract of Aswagandha did not show any inhibitory potential, as the corresponding IC50 values was $>100 \mu \mathrm{g} / \mathrm{ml}$ towards all the three specified CYP isoenzymes (49). Interestingly this matches with the already published literature for Remdesivir, showing it as a weak inhibitor of CYP3A4 (50). Whereas for the Aswagandha our results match with the observations published by Patil et. al. showing aqueous extracts prepared as per Ayurvedic procedure does not show inhibitory effects on CYP3A4 $(12,24,32)$. In addition, Aswagandha in combination with remdesivir exhibited IC50 $>100 \mu \mathrm{g} / \mathrm{ml}$ which confirmed the weak inhibitory potential of remdesivir also in the presence aqueous extract of Aswagandha. This indicates that the combination of Withania somnifera and remdesivir, or any other drug which is the substrate of CYP3A4, 2D6, 2C8 might be safe to use for better pharmacotherapy.

Furthermore, we also identified the HDIs of polyherbal formulation (AYUSH-64) alone and in combination with the case control drug remdesivir. Results obtained signify that AYUSH-64 had no inhibitory interaction with CYP3A4 and CYP2D6 as IC50 values were found be $>100 \mu \mathrm{g} / \mathrm{ml}$. While, it showed a weak or moderate inhibitory interaction with CYP2C8 with an IC50 of $63.44 \pm 14.9$. It is therefore inferred that AYUSH-64 will be safe to administer with the substrates of CYP3A4 and 2D6, while a caution should be observed with drugs that are substrates of CYP2C8. Moreover, the action of AYUSH-64 in combination with remdesivir showed no inhibitory kind of interaction towards CYP3A4 and 2D6 with which IC50 was $>100 \mu \mathrm{g} / \mathrm{ml}$. As specified before both the AYUSH-64 and remdesivir showed weak or moderate interactions towards CYP2C8, the IC50 of the combination showed $85.21 \pm 18.3$. Indeed, this fall of IC50 within the inhibitory limit confer that of these two together may competitively binds to substrate and showed moderate inhibition towards CYP2C8. The HDIs and pharmacokinetic parameters presented in the current study may provide insights to develop new and safe therapeutic regimen to mitigate SARS-CoV-2 and also provides safety profile to use concomitantly with other drugs. However, the study could not did focused on time dependant inhibition and induction type of Pharmacokinetic HDIs. Therefore, further, in-vivo and clinical HDIs studies should be performed in future for the translational understanding and better outcomes.

\section{Conclusions}

Generally, the combinatorial function of Ayurvedic extracts as an adjuvant with conventional drugs may produce beneficial effects. To make those favourable therapeutics outcomes to clinically practicable, it is necessary to have data regarding risks assessments (herb-drug interactions) for safe pharmacotherapy. The bioactive compounds of Aswagandha and AYUSH-64 which were already known to elicit immunomodulatory activity and antiviral properties might be suitable to prevent and treat COVID-19. In-silico study of the identified compounds showed CYP inhibitory affinity. Furthermore, the performed in-vitro CYP inhibition studies of plant extract along with case control drug (Remdesivir) revealed that Aswagandha may be safe to co-administer with the substrates of CYP3A4. 2C8, and 2D6. AYUSH-64 might not show any interactions towards CYP3A4, 2D6, while it might exhibit moderate interactions towards CYP2C8. Our study depicts the interactions of the herbs along with the case control drug that provides a practicable insight of their safe and concomitant administration in other comorbidities.

\section{Declarations}

\section{Conflicts of Interest: None}

7. Acknowledgements: Authors are thankful to Ms Vedika Bhat for her timely and quick assistance related to in-silico work. Authors express deep sense of gratitude for the help received from Mr. Jaimin Chaudhary in CYP protocol development. The help from Mr. Vipin, and Mr. Sonu Kumar Gupta also acknowledged for support in analytical lab. Authors expresses gratitude to the Ministry of AYUSH and Department of Biotechnology (DBT), Government of India for jointly funding this study (BT/PR40738/TRM/120/486/2020 \& A.11019/03/2020NMPB-IV-A). 'SSK' has received the Fellowship from this project. Authors are thankful to Dr. Girish Tillu and Dr. Preeti Chavan-Gautam for timely discussion on Ayurveda concepts. Authors express their gratitude to Prof. Bhushan Patwardhan for the timely guidance and Dr. N. Srikanth DG-CCRAS for providing the AYSUH extracts (test material) and support to carry-out this work. Authors are thankful to Ministry of AYUSH's, Center of Excellence (AYUSH-CoE), Savitribai Phule Pune University, Pune and DBT-Translational Health Science and Technology Institute (THSTI) for providing all the necessary facilities. 


\section{References}

1. Rakel D. Preface. In: Rakel D, editor. Integrative Medicine (Fourth Edition): Elsevier; 2018. p. xvii.

2. Borse SP, Singh DP, Nivsarkar M. Understanding the relevance of herb-drug interaction studies with special focus on interplays: a prerequisite for integrative medicine. Porto Biomed J. 2019;4(2):e15.

3. Fugh-Berman A. Herb-drug interactions. Lancet. 2000;355(9198):134-8.

4. Gordon A, Buch Z, Baute V, Coeytaux R. Use of Ayurveda in the Treatment of Type 2 Diabetes Mellitus. Glob Adv Health Med. 2019;8:2164956119861094.

5. Toukabri I, Said AB, Hamdi A, Mokrani A, Gabsi A, Ayed WB, et al. Patterns of complementary and alternative medicine use among Tunisian cancer patients. J Oncol Pharm Pract. 2020:1078155220980131.

6. Hung HH, Chen WC, Chen YH, Chiu LT, Chen HY. Evaluation of the efficacy of Chinese herbal medicine and acupuncture for the prevention of mental disorders in interstitial cystitis patients: A nationwide population-based study. Medicine (Baltimore). 2020;99(30):e21422.

7. Rees L, Weil A. Integrated medicine. BMJ. 2001;322(7279):119-20.

8. Wainapel SF, Rand S, Fishman LM, Halstead-Kenny J. Integrating complementary/alternative medicine into primary care: evaluating the evidence and appropriate implementation. Int J Gen Med. 2015;8:361-72.

9. Winters M. Ancient medicine, modern use: Withania somnifera and its potential role in integrative oncology. Altern Med Rev. 2006;11(4):269-77.

10. Kotecha R. The journey with COVID-19: Initiatives by Ministry of AYUSH. J Ayurveda Integr Med. 2021;12(1):1-3.

11. Chaturvedi S, Kumar N, Tillu G, Deshpande S, Patwardhan B. AYUSH, modern medicine and the Covid-19 pandemic. Indian J Med Ethics. 2020;-(-):1-4.

12. Borse S, Joshi M, Saggam A, Bhat V, Walia S, Marathe A, et al. Ayurveda botanicals in COVID-19 management: An in silico multi-target approach. PLoS One. 2021;16(6):e0248479.

13. Patwardhan B, Chavan-Gautam P, Gautam M, Tillu G, Chopra A, Gairola S, et al. Ayurveda rasayana in prophylaxis of COVID19. Curr Sci. 2020;118(8):1158-60.

14. Chopra A, Srikanth N, Patwardhan B, Group ACR. Withania somnifera as a safer option to hydroxychloroquine in the chemoprophylaxis of COVID-19: Results of interim analysis. Complement Ther Med. 2021;62:102768.

15. Saggam A, Limgaokar K, Borse S, Chavan-Gautam P, Dixit S, Tillu G, et al. Withania somnifera (L.) Dunal: Opportunity for Clinical Repurposing in COVID-19 Management. Front Pharmacol. 2021;12:623795.

16. Bhapkar V, Sawant T, Bhalerao S. A critical analysis of CTRI registered AYUSH studies for COVID- 19. J Ayurveda Integr Med. 2020.

17. Babos MB, Heinan M, Redmond L, Moiz F, Souza-Peres JV, Samuels V, et al. HerbDrug Interactions: Worlds Intersect with the Patient at the Center. Medicines (Basel). 2021;8(8).

18. Fasinu PS, Bouic PJ, Rosenkranz B. An overview of the evidence and mechanisms of herb-drug interactions. Front Pharmacol. 2012;3:69.

19. Ogu CC, Maxa JL. Drug interactions due to cytochrome P450. Proc (Bayl Univ Med Cent). 2000;13(4):421-3.

20. Rosenkranz B, Fasinu P, Bouic P. An Overview of the Evidence and Mechanisms of Herb-Drug Interactions. Frontiers in Pharmacology. 2012;3:69.

21. Patwardhan B. Ayurveda and integrative medicine: Riding a tiger. J Ayurveda Integr Med. 2010;1(1):13-5.

22. Kamboj P, Sarkar S, Gupta SK, Bisht N, Kumari D, Alam MJ, et al. Methanolic Extract of Lysimachia Candida Lindl. Prevents High-Fat High-Fructose-Induced Fatty Liver in Rats: Understanding the Molecular Mechanism Through Untargeted Metabolomics Study. Front Pharmacol. 2021;12:653872.

23. Daina A, Michielin O, Zoete V. SwissADME: a free web tool to evaluate pharmacokinetics, drug-likeness and medicinal chemistry friendliness of small molecules. Scientific Reports. 2017;7(1):42717.

24. Patil D, Gautam M, Gairola S, Jadhav S, Patwardhan B. Effect of botanical immunomodulators on human CYP3A4 inhibition: implications for concurrent use as adjuvants in cancer therapy. Integr Cancer Ther. 2014;13(2):167-75.

Page $9 / 13$ 
25. Wu J, Shaw J, Dubaisi S, Valeriote F, Li J. In vitro metabolism and drug-drug interaction potential of UTL-5g, a novel chemoand radioprotective agent. Drug Metab Dispos. 2014;42(12):2058-67.

26. Kerry NL, Somogyi AA, Bochner F, Mikus G. The role of CYP2D6 in primary and secondary oxidative metabolism of dextromethorphan: in vitro studies using human liver microsomes. Br J Clin Pharmacol. 1994;38(3):243-8.

27. Humeniuk R, Mathias A, Cao H, Osinusi A, Shen G, Chng E, et al. Safety, Tolerability, and Pharmacokinetics of Remdesivir, An Antiviral for Treatment of COVID-19, in Healthy Subjects. Clin TransI Sci. 2020;13(5):896-906.

28. Gogte VM. Ayurvedic pharmacology and therapeutic uses of medicinal plants (Dravyagunavigyan), Bharatiya Vidya Bhavan (SPARC). Mumbai Publications; 2000.

29. Mishra NK, Agarwal S, Raghava GP. Prediction of cytochrome P450 isoform responsible for metabolizing a drug molecule. BMC Pharmacol. 2010;10:8.

30. Winslow LC, Kroll DJ. Herbs as medicines. Arch Intern Med. 1998;158(20):2192-9.

31. Haupt LJ, Kazmi F, Ogilvie BW, Buckley DB, Smith BD, Leatherman S, et al. The Reliability of Estimating Ki Values for Direct, Reversible Inhibition of Cytochrome P450 Enzymes from Corresponding IC50 Values: A Retrospective Analysis of 343 Experiments. Drug Metab Dispos. 2015;43(11):1744-50.

32. Borse SP, Kamble BB. Effects of Ayurvedic Rasayana botanicals on CYP3A4 isoenzyme system. J Integr Med. 2015;13(3):165-72.

33. Mei M, Tan X. Current Strategies of Antiviral Drug Discovery for COVID-19. Front Mol Biosci. 2021;8:671263.

34. Parasher A. COVID-19: Current understanding of its Pathophysiology, Clinical presentation and Treatment. Postgrad Med J. 2021;97(1147):312-20.

35. Sofowora A, Ogunbodede E, Onayade A. The role and place of medicinal plants in the strategies for disease prevention. Afr $\mathrm{J}$ Tradit Complement Altern Med. 2013;10(5):210-29.

36. Mani JS, Johnson JB, Steel JC, Broszczak DA, Neilsen PM, Walsh KB, et al. Natural product-derived phytochemicals as potential agents against coronaviruses: A review. Virus Res. 2020;284:197989.

37. Izzo AA, Ernst E. Interactions between herbal medicines and prescribed drugs: an updated systematic review. Drugs. 2009;69(13):1777-98.

38. Girme A, Saste G, Pawar S, Balasubramaniam AK, Musande K, Darji B, et al. Investigating 11 Withanosides and Withanolides by UHPLC-PDA and Mass Fragmentation Studies from Ashwagandha (Withania somnifera). ACS Omega. 2020;5(43):2793343.

39. Gundeti MS, Bhurke LW, Mundada PS, Murudkar S, Surve A, Sharma R, et al. AYUSH 64, a polyherbal Ayurvedic formulation in Influenza-like illness - Results of a pilot study. J Ayurveda Integr Med. 2020.

40. Ram TS, Munikumar M, Raju VN, Devaraj P, Boiroju NK, Hemalatha R, et al. In silico evaluation of the compounds of the ayurvedic drug, AYUSH-64, for the action against the SARS-CoV-2 main protease. J Ayurveda Integr Med. 2021.

41. Kar P, Kumar V, Vellingiri B, Sen A, Jaishee N, Anandraj A, et al. Anisotine and amarogentin as promising inhibitory candidates against SARS-CoV-2 proteins: a computational investigation. J Biomol Struct Dyn. 2020:1-11.

42. Ekor M. The growing use of herbal medicines: issues relating to adverse reactions and challenges in monitoring safety. Front Pharmacol. 2014;4:177.

43. Zhou SF, Xue CC, Yu XQ, Li C, Wang G. Clinically important drug interactions potentially involving mechanism-based inhibition of cytochrome P450 3A4 and the role of therapeutic drug monitoring. Ther Drug Monit. 2007;29(6):687-710.

44. Desta Z, Flockhart DA. Chapter 18 - Pharmacogenetics of Drug Metabolism. In: Robertson D, Williams GH, editors. Clinical and Translational Science (Second Edition): Academic Press; 2017. p. 327-45.

45. Tirona RG, Kim RB. Chapter 20 - Introduction to Clinical Pharmacology. In: Robertson D, Williams GH, editors. Clinical and Translational Science (Second Edition): Academic Press; 2017. p. 365-88.

46. Eastman RT, Roth JS, Brimacombe KR, Simeonov A, Shen M, Patnaik S, et al. Remdesivir: A Review of Its Discovery and Development Leading to Emergency Use Authorization for Treatment of COVID-19. ACS Cent Sci. 2020;6(5):672-83.

47. use Soc. Summary on compassionate use of Remdesivir. European Medical Agency. 03-04-2020;EMA/178637/2020 - Rev.2. 
48. Deb S, Reeves AA, Hopefl R, Bejusca R. ADME and Pharmacokinetic Properties of Remdesivir: Its Drug Interaction Potential. Pharmaceuticals (Basel). 2021;14(7).

49. Savai J, Varghese A, Pandita N, Chintamaneni M. Investigation of CYP3A4 and CYP2D6 Interactions of Withania somnifera and Centella asiatica in Human Liver Microsomes. Phytother Res. 2015;29(5):785-90.

50. Yang K. What do we know about remdesivir drug interactions? Clinical and translational science. 2020;13(5):842.

\section{Figures}
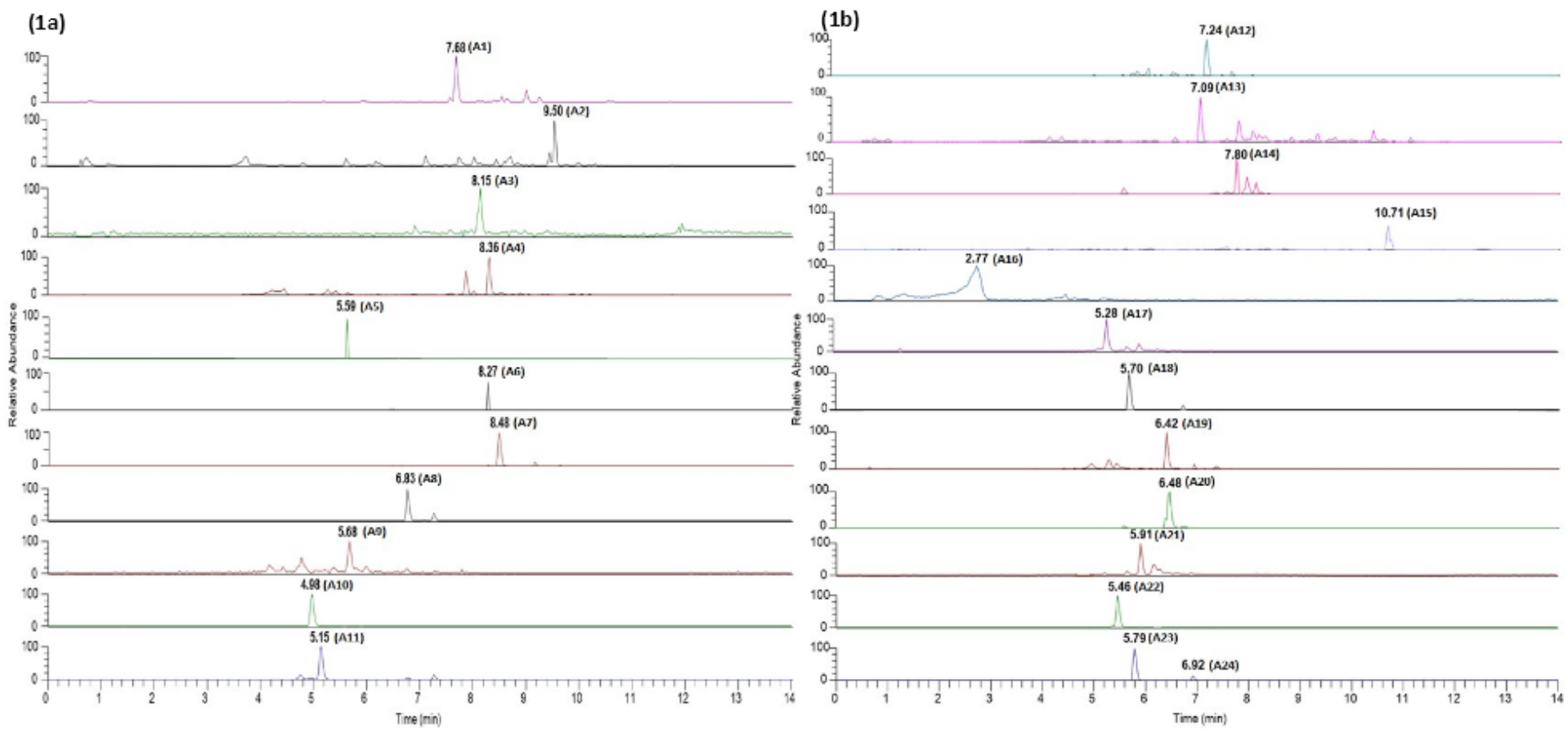

Figure 1

Extracted chromatograms of identified phytoconstituents of AYUSH-64. (1a) comprising compounds A (1-11); whereas, Betulin (A1), Neocaesalpin B (A2), Formononetin (A3), Burnamine (A4), Picrinine (A5), Vallesamine (A6), Oleanolic Acid (A7), Amarogentin (A8), Gentianine (A9), Mangiferin (A10), Sweroside (A11) and (1b) comprising A (12-24); Kaempferol (A12), 5-methoxystrictamine (A13), Neocaesalpin L (A14), Beta-Caesalpin (A15), Gallic acid (A16), Picroside B (A17), Verminoside (A18), Swertianolin (A19), Minecoside (A20), Apocynin (A21), Picroside-IV (A22), Kutkoside (A23), and Picroside-II (A24). 


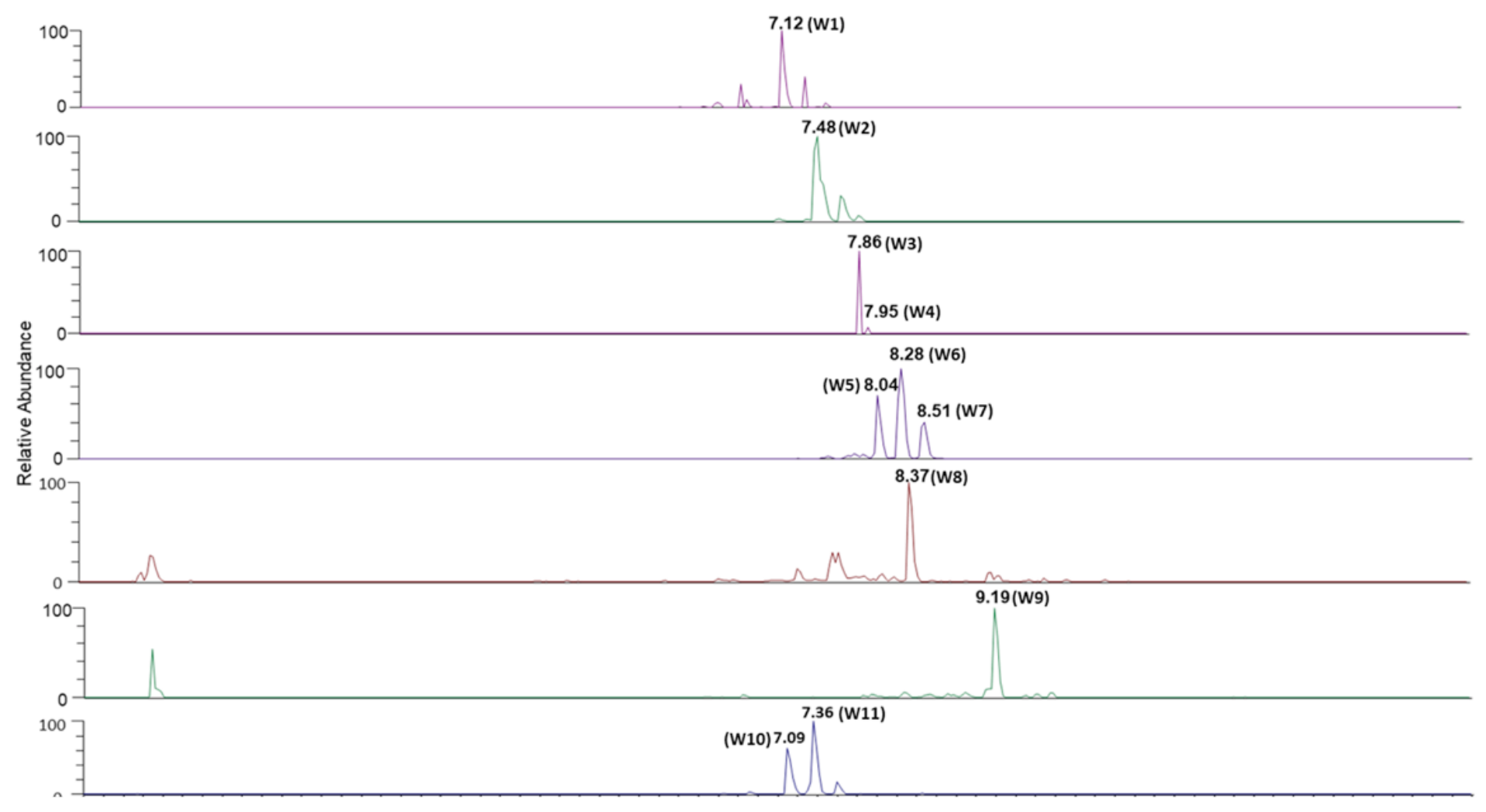

Figure 2

Extracted chromatograms of identified phytoconstituents of Withania somnifera comprising W (1-11); whereas, Withanoside VII (W1), Viscosalactone B (W2), Dihydrowithaferin A (W3), Withanoside V (W4), Withaferin A (W5), 12-deoxywithastramonolide (W6), Withanolide A (W7), 27-hydroxy withanone (W8), Withanolide B (W9), Withanoside X (W10), Coagulin Q (W11)

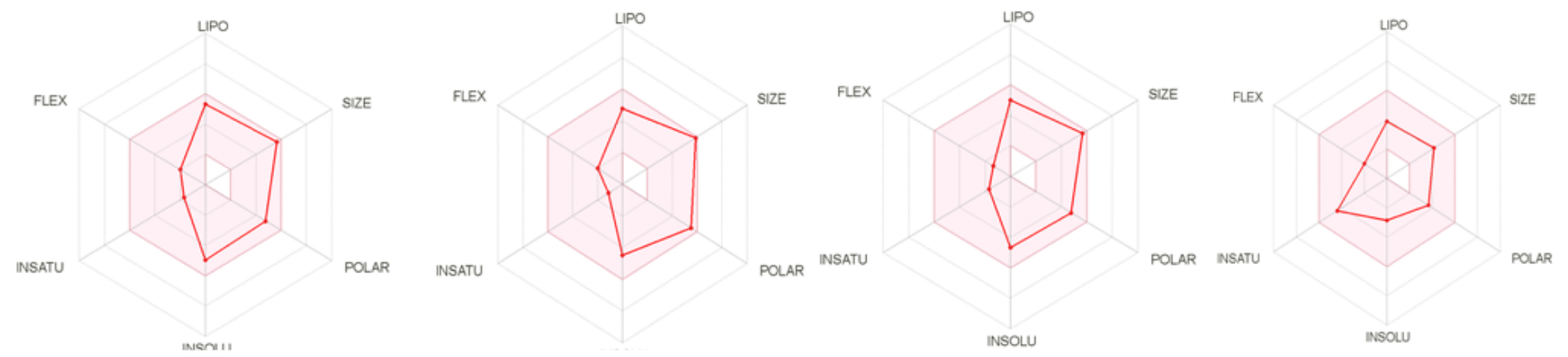


Figure 3

Illustrates the radar plots of key phytoconstituents identified from AYUSH-64 and Withania somnifera

\section{Figure 4}

Effect different concentrations of A) Ketoconazole (5.00-0.0005 $\mu \mathrm{M} / \mathrm{ml})$, B) Remdesivir (1000 - $1 \mathrm{ng} / \mathrm{ml})$, C) Remdesivir + AYUSH64 (2001- $1.001 \mu \mathrm{g} / \mathrm{ml})$, D) AYUSH-64 (2000- $1 \mu \mathrm{g} / \mathrm{ml})$, E) Withania somnifera (2000- $1 \mu \mathrm{g} / \mathrm{ml}), \mathrm{F})$ Remdesivir + Withania somnifera $(2001-1.001 \mu \mathrm{g} / \mathrm{ml})$ on CYP3A4-mediated hydroxylation of testosterone. The graphs were plotted between log conc. Vs. percentage of inhibition.

\section{Figure 5}

Effect different concentrations of A) Rosiglitazone (100-0.01 $\mu \mathrm{M} / \mathrm{ml}), \mathrm{B})$ Remdesivir (1000 - $1 \mathrm{ng} / \mathrm{ml})$, C) Remdesivir + AYUSH-64 (2001- $1.001 \mu \mathrm{g} / \mathrm{ml})$, D) AYUSH-64 (2000- $1 \mu \mathrm{g} / \mathrm{ml})$, E) Withania somnifera (2000- $1 \mu \mathrm{g} / \mathrm{ml}), \mathrm{F})$ Remdesivir + Withania somnifera $(2001-1.001 \mu \mathrm{g} / \mathrm{ml})$ on CYP2C8-mediated hydroxylation of paclitaxel. The graphs were plotted between log conc. Vs. percentage of inhibition.

\section{Figure 6}

Effect different concentrations of A) Quinidine (100-0.01 $\mu \mathrm{M} / \mathrm{ml})$, B) Remdesivir (1000 - $1 \mathrm{ng} / \mathrm{ml})$, C) Remdesivir + AYUSH-64 (2001-

$1.001 \mu \mathrm{g} / \mathrm{ml})$, D) AYUSH-64 (2000- $1 \mu \mathrm{g} / \mathrm{ml})$, E) Withania somnifera (2000- $1 \mu \mathrm{g} / \mathrm{ml}), \mathrm{F})$ Remdesivir + Withania somnifera (2001$1.001 \mu \mathrm{g} / \mathrm{ml}$ ) on CYP2D6-mediated hydroxylation of dextromethorphan. The graphs were plotted between log conc. Vs. percentage of inhibition.

\section{Supplementary Files}

This is a list of supplementary files associated with this preprint. Click to download.

- S1.File.pptx

- S2.File.docx

- S3.File.docx

- S4.File.docx

- Onlinefloatimage1.png 